\title{
Aku Anak Disiplin Game: Media Edukatif Sebagai Solusi Kreatif dalam Penanaman Karakter Disiplin pada Anak Sekolah Dasar
}

\author{
Tangge M. Said \\ Unit Pelaksana Teknis Sekolah Dasar Negeri Inpres Bertingkat Kabupaten Pinrang Indonesia \\ tanggesaid@gmail.com
}

\begin{abstract}
Abstract. The purpose of writing this scientific paper is to find out the design and application of educational media ANDI (Aku Anak Disciplin) game as a creative solution in instilling discipline character in elementary school children. The type of writing in this paper is a literature study (library research). The data obtained are presented descriptively so that it shows a scientific study that can be further developed and applied through the concept of ANDI (Aku Anak Disciplin) game: educative media as a creative solution in instilling discipline character in elementary school children. The implementation of the media, the teacher as a facilitator not only provides an identification of the character of discipline to students but also every character of the discipline that exists in the game must be applied in the school environment. So that students get a response (results) from the game and accidentally students will easily remember the attitude of discipline that must be applied and experience habituation in doing so.
\end{abstract}

Keywords: Elementary School Children, Disciplinary Character, Educative Media

\begin{abstract}
Abstrak. Tujuan penulisan karya tulis ilmiah ini adalah untuk mengetahui desain dan penerapan media edukatif ANDI (Aku Anak Disiplin) game sebagai solusi kreatif dalam penanaman karakter disiplin pada anak sekolah dasar. Jenis tulisan dalam karya tulis ini bersifat kajian pustaka (library research). Data yang diperoleh disajikan secara deskriptif sehingga menunjukkan suatu kajian ilmiah yang dapat dikembangkan dan diterapkan lebih lanjut melalui konsep ANDI (Aku Anak Disiplin) game: media edukatif sebagai solusi kreatif dalam penanaman karakter disiplin pada anak sekolah dasar. Implementasi dari media tersebut, guru sebagai fasilitator tidak hanya sekadar memberikan pengidentifikasian karakter disiplin kepada siswa tetapi juga setiap karakter disiplin yang ada pada permainan tersebut harus diaplikasikan di lingkungan sekolah. Sehingga siswa mendapat respon (hasil) dari permainan tersebut dan secara tidak sengaja siswa akan mudah mengingat sikap disiplin yang harus diterapkan dan mengalami pembiasaan dalam melakukannya.
\end{abstract}

Kata kunci: Anak Sekolah Dasar, Karakter Disiplin, Media Edukatif 


\section{PENDAHULUAN}

Penguatan pendidikan karakter di era sekarang merupakan hal yang penting untuk dilakukan mengingat banyaknya peristiwa yang menunjukkan terjadinya krisis moral baik di kalangan anak-anak, remaja, maupun orang tua. Hal ini sejalan dengan Pendidikan Nasional Indonesia yang berdasarkan Pancasila dalam Undang-Undang Republik Indonesia Nomor 20 Tahun 2003 bertujuan untuk berkembangnya potensi peserta didik agar menjadi manusia yang beriman dan bertakwa kepada Tuhan Yang Maha Esa, berakhlak mulia, sehat, berilmu, cakap, kreatif, mandiri, dan menjadi warga negera yang demokratis serta bertanggung jawab. Oleh karena itu, penguatan pendidikan karakter perlu dilaksanakan sedini mungkin dimulai dari lingkungan keluarga, sekolah, dan meluas ke dalam lingkungan masyarakat.

Salah satu nilai karakter yang perlu dikembangkan adalah disiplin (Firdaus, 2019). Nilai karakter disiplin sangat penting dimiliki oleh manusia agar kemudian muncul nilai-nilai karakter yang baik lainnya. Pentingnya penguatan nilai karakter disiplin didasarkan pada alasan bahwa sekarang banyak terjadi perilaku menyimpang yang bertentangan dengan norma kedisiplinan. Perilaku tidak disiplin yang lain contohnya adalah membuang sampah sembarangan, parkir tidak di tempat yang telah ditentukan, tidak mematuhi perizinan mendirikan bangunan, dan sebagainya. Adanya perilaku melanggar tersebut menunjukkan belum adanya kesadaran masyarakat untuk berperilaku disiplin terhadap aturan yang telah ditetapkan pemerintah.

Perilaku tidak disiplin juga sering ditemui di lingkungan sekolah, termasuk sekolah dasar. Terjadinya perilaku tidak disiplin di sekolah tersebut menunjukkan bahwa telah terjadi permasalahan serius dalam hal pendidikan karakter disiplin. Munculnya perilaku tidak disiplin menunjukkan bahwa pengetahuan yang terkait dengan karakter yang didapatkan siswa di sekolah tidak membawa dampak positif terhadap perubahan perilaku siswa sehari-hari. Pada dasarnya, siswa tahu bahwa perilakunya tidak benar tetapi mereka tidak memiliki kemampuan untuk membiasakan diri menghindari perilaku yang salah tersebut. Hal ini merupakan dalam proses pendidikan karakter yang terjadi. Bisa jadi, pendidikan karakter yang dilakukan selama ini baru pada tahap pengetahuan saja, belum sampai pada perasaan dan perilaku yang berkarakter (Wuryandani dkk., 2014: 286).

Proses pembelajaran lebih banyak mengajarkan siswa pengetahuan verbalistik yang kurang mempersiapkan siswa agar mampu menghadapi kehidupan sosial yang akan mereka temui. Hal ini senada dengan yang dituliskan oleh Suparno (2012: 8) bahwa pendidikan kita masih terlalu menekankan segi kognitif. Ini pun masih terbatas pada mencari angka, bukan kemampuan analisis kritis siswa terhadap peristiwa yang dihadapi dalam kehidupan sehari-hari. Pendapat serupa disampaikan pula oleh Sugirin (2010: 267) bahwa tolok ukur keberhasilan pendidikan selalu mengacu pada prestasi siswa yang terkait dengan ranah kognitif dan psikomotorik.

Suryadi (2012: 96) menjelaskan bahwa penyebab utama terjadinya krisis moral dan karakter di kalangan peserta didik adalah terjadinya dikotomisasi yaitu pemisahan secara tegas antara pendidikan intelektual di satu pihak dan pendidikan nilai di lain pihak. Padahal jika mendasarkan pada pendapat Bloom (1979: 7) ada tiga domain dalam pembelajaran yaitu kognitif, afektif, dan psikomotor. Ketiga domain tersebut harus dikembangkan secara komprehensif dalam pembelajaran. Sekolah sebagai lembaga pendidikan formal perlu memberikan perhatian khusus terhadap pendidikan karakter sesuai dengan pendapat Johanson dkk., (2011: 109) bahwa sekolah merupakan lembaga dalam mempersiapkan siswa untuk hidup, baik secara akademis dan sebagai agen moral di masyarakat.

Pendidikan di sekolah dasar merupakan jenjang pendidikan formal pertama yang akan menentukan arah pengembangan potensi peserta didik. Oleh karena itu, di sekolah dasar perlu mengembangkan karakter disiplin siswa secara optimal sehingga harapannya di tingkat selanjutnya siswa sudah memiliki bekal perilaku disiplin yang 
kuat. Mengingat demikian pentingnya pendidikan karakter disiplin di sekolah dasar, maka perlu dilakukan berbagai kebijakan sekolah yang dapat mendukung keberhasilan pendidikan karakter disiplin secara optimal (Wuryandani dkk., 2014: 287-288).

Menanggapi permasalahan di atas, maka penulis menawarkan solusi cerdas dan kreatif yaitu ANDI (Aku Anak Disiplin) Game: Media Edukatif Sebagai Solusi Kreatif dalam Penanaman Karakter Disiplin pada Anak Sekolah Dasar. Permainan ANDI (Aku Anak Disiplin) merupakan media pembelajaran pendidikan karakter yang mengajarkan mengenai pentingnya penerapan sikap disiplin dalam kehidupan sehari-hari. Permainan ini memberikan gambaran jelas kepada anak-anak tentang contohcontoh sikap disiplin di rumah, di sekolah, dan di lingkungan masyarakat. Aku Anak Disiplin merupakan permainan yang diadaptasi dari permainan Ular Tangga yang dimodifikasi dengan kreatif dan inovatif sehingga menarik dan menyenangkan untuk dimainkan. Permainan ini dimainkan dengan menggunakan alat yang sama pada permainan Ular Tangga dan disertai dengan penggunaan tiga jenis kartu yaitu kartu anak disiplin (discipline child card), kartu prestasi (achievement card), dan kartu hukuman (penalty card).

Adapun Tujuan penulisan karya tulis ilmiah ini adalah untuk mengetahui desain dan penerapan media edukatif ANDI (Aku Anak Disiplin) game sebagai solusi kreatif dalam penanaman karakter disiplin pada anak sekolah dasar.

\section{METODE PENELITIAN}

Jenis tulisan dalam karya tulis ini bersifat kajian pustaka (library research). Data yang diperoleh disajikan secara deskriptif sehingga menunjukkan suatu kajian ilmiah yang dapat dikembangkan dan diterapkan lebih lanjut melalui konsep ANDI (Aku Anak Disiplin) game: media edukatif sebagai solusi kreatif dalam penanaman karakter disiplin pada anak sekolah dasar.

Objek penulisan dalam penulisan karya tulis ini adalah ANDI (Aku Anak Disiplin) game: media edukatif sebagai solusi kreatif dalam penanaman karakter disiplin pada anak sekolah dasar dengan harapan dapat diaplikasikan secara optimal dalam kehidupan sehari-hari. Data-data yang diperoleh dalam karya tulis ini dari berbagai literatur seperti, buku, jurnal, koran dan referensi artikel yang diperoleh dari internet yang relevan dengan permasalahan yang diangkat.

Penulisan karya tulis ini diawali dengan pengumpulan data dan informasi yang sesuai selanjutnya diseleksi dan direduksi kerelevannya dengan masalah yang dibahas kemudian permasalahan dianalisis dengan jelas yang dilakukan secara deskriptif sehingga menghasilkan sebuah karya tulis ilmiah.

\section{PEMBAHASAN}

Permainan Aku Anak Disiplin merupakan media pembelajaran pendidikan karakter yang mengajarkan mengenai pentingnya penerapan sikap disiplin dalam kehidupan sehari-hari. Permainan ini memberikan gambaran jelas kepada anak-anak tentang contoh-contoh sikap disiplin di rumah, di sekolah, dan di lingkungan masyarakat.

Aku Anak Disiplin merupakan permainan yang diadaptasi dari permainan Ular Tangga yang dimodifikasi dengan kreatif dan inovatif sehingga menarik dan menyenangkan untuk dimainkan. Permainan ini dimainkan dengan menggunakan alat yang sama pada permainan Ular Tangga dan disertai dengan penggunaan tiga jenis kartu yaitu kartu anak disiplin (discipline child card), kartu prestasi (achievement card), dan kartu hukuman (penalty card). Adapun tipe kartu pada ANDI (Aku Anak Disiplin) game ini, yaitu:

1. Kartu Anak Disiplin (Discipline Child Card) berisi gambar-gambar contoh perilaku disiplin dan tidak disiplin di rumah, di sekolah, dan di lingkungan masyarakat yang dilengkapi penjelasan mengenai gambar tersebut. Keberadaan kartu ini bertujuan untuk memberikan gambaran mengenai contoh perilaku disiplin agar kiranya dapat ditiru dalam kehidupan sehari-hari dan gambaran mengenai contoh perilaku tidak disiplin agar kiranya tidak ditiru dan dijadikan referensi dalam mencegah diri berperilaku tidak disiplin. 
2. Kartu Prestasi (Achievement Card) menampilkan tulisan mengenai contoh perilaku disiplin dan disertai petunjuk yang harus dilaksanakan pemain. Kartu ini berisi pujian kepada pemain yang seakan-akan telah melakukan perilaku disiplin. Hal ini bertujuan untuk menstimulus pemain (anak-anak) agar melaksanakan perilaku disiplin yang dicontohkan dalam kehidupan sehari-hari.

3. Kartu Hukuman (Penalty Card) menampilkan tulisan mengenai contoh perilaku tidak disiplin dan disertai petunjuk yang harus dilaksanakan pemain. Kartu ini berisi teguran atau sindiran kepada pemain yang seakan-akan telah melakukan penyimpangan perilaku disiplin. Hal ini bertujuan untuk menstimulus pemain (anakanak) agar menghindari penyimpangan perilaku disiplin yang dicontohkan dan menjelaskan kepada pemain (anak-anak) bahwa setiap pelanggaran akan ada ganjarannya.

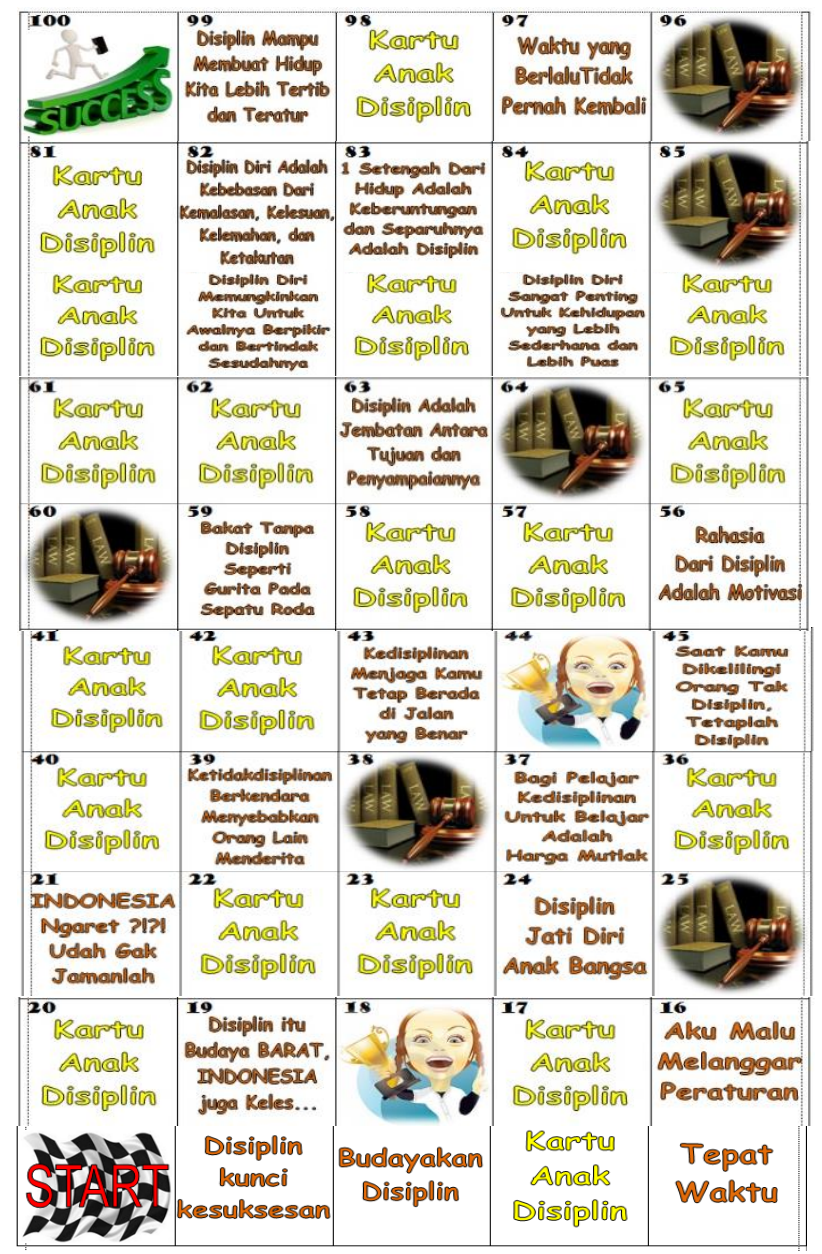

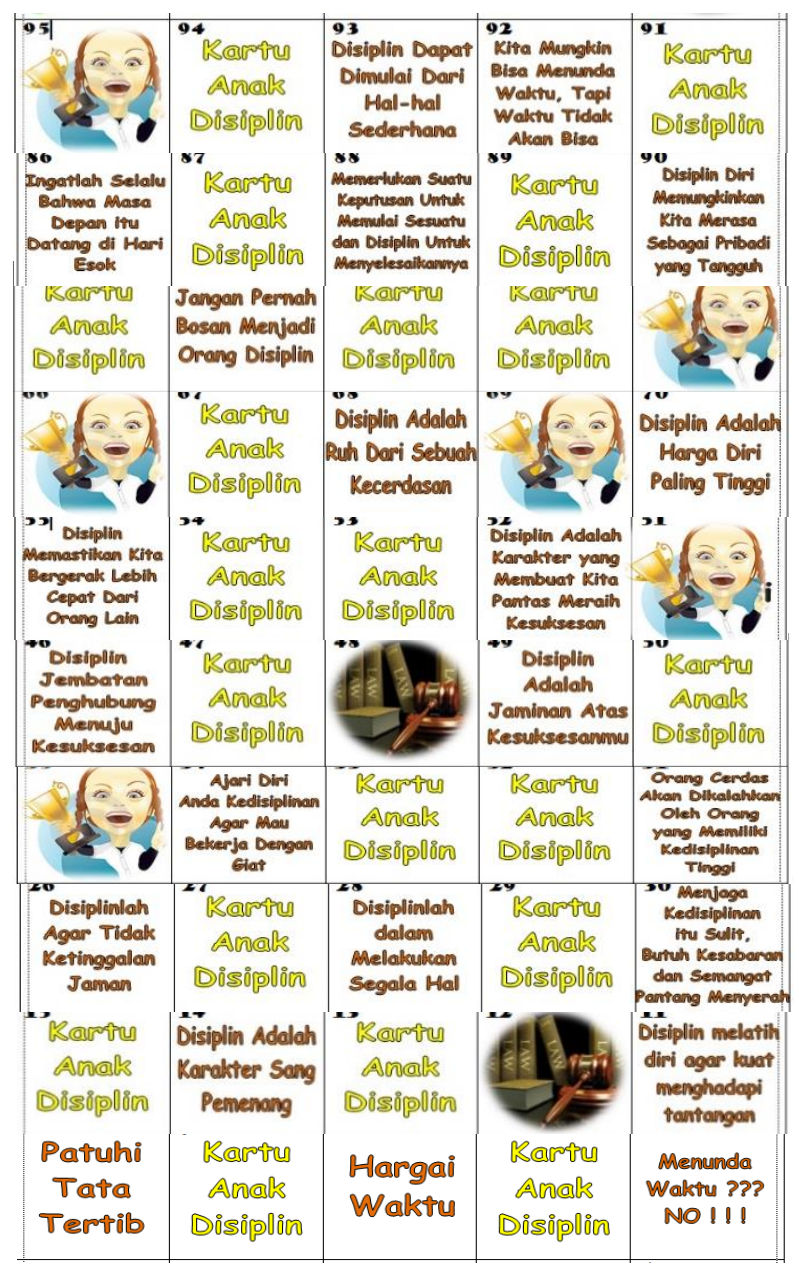

Gambar 1. Alas ANDI (Aku Anak Disiplin) Game
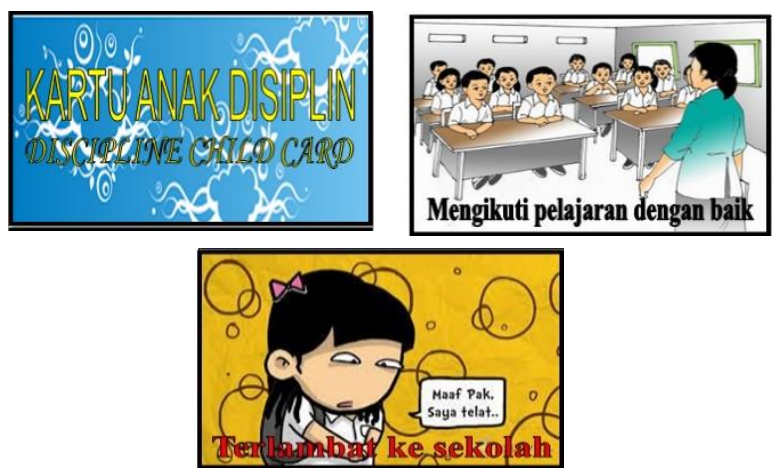

Gambar 1. Kartu Disiplin
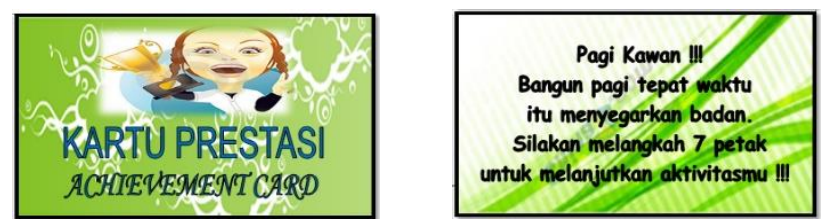

Gambar 3. Kartu Prestasi 


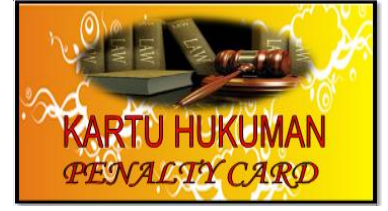

Gambar 4. Kartu Hukuman

Adapun peraturan ANDI (Aku Anak Disiplin) Game, yaitu sebagai berikut:

1. Permainan ini dimainkan minimal 2 orang dan maksimal 5 orang.

2. Setiap pemain memiliki 3 kali kesempatan melempar dadu untuk memulai permainan. Pemain yang mendapatkan dadu bermata 6, maka berhak memasuki area start. Kemudian diberi kesempatan untuk melempar kembali dadu agar dapat melangkah ke kotak selanjutnya.

3. Pemain akan menemukan petunjuk dalam kotak, diantaranya:

a. Tulisan "Kartu Anak Disiplin" memberikan petunjuk kepada pemain untuk mengambil selembar kartu anak disiplin per kotak lalu di akhir permainan, pemain menyusun kartu tersebut dengan cara mengelompokkan mana kartu yang menunjukkan sikap disiplin dan mana yang tidak. Pengelompokkan yang benar untuk satu kartu diberi nilai 100 poin dan pengelompokkan yang salah untuk satu kartu diberi nilai -25 .

b. Gambar "Kartu Prestasi" memberikan petunjuk kepada pemain untuk mengambil selembar kartu prestasi per kotak lalu melaksanakan perintah yang tercantum pada kartu tersebut. Satu kartu prestasi diberi nilai 150 poin.

c. Gambar "Kartu Hukuman" memberikan petunjuk kepada pemain untuk mengambil selembar kartu prestasi per kotak lalu melaksanakan perintah yang tercantum pada kartu tersebut. Satu kartu hukuman diberi nilai -50 poin.

d. Gambar "Ular dan Tangga" memberikan petunjuk kepada pemain untuk berpindah posisi sesuai arah gambar ular atau tangga tersebut. Kegiatan ini tidak diberi nilai. e. Selain itu, pemain juga akan menemukan tulisan-tulisan motivasi yang memberikan semangat kepada pemain tentang pentingnya berdisiplin dalam kehidupan sehari-hari. Kegiatan ini tidak diberi nilai.

4. Pemenang dalam permainan ditentukan oleh total akumulasi nilai yang diperoleh pemain bukan cepatnya mengakhiri permainan pada kotak finish.

Dalam mengimplementasikan permainan ini dibutuhkan seorang fasilitator sebagai pengarah atau juri. Adapun peran dan fungsi fasilitator, yaitu sebagai berikut:

1. Guru, orang tua, atau yang mewakili selaku fasilitator memiliki kewenangan untuk menjadi juri dalam permainan "Aku Anak Disiplin" sesuai kesepakatan bersama.

2. Fasilitator menjelaskan kepada pemain mengenai dampak karakter yang ditimbulkan pada kartu anak disiplin, kartu prestasi, dan kartu hukuman serta tulisan yang tertera pada kotak agar mereka paham maksud dari gambar dan tulisan tersebut.

3. Fasilitator meminta kepada pemain yang kalah diharuskan menulis pengalaman ketidakdisiplinan yang pernah dilakukannya serta akibat yang ditimbulkan dari perilaku tersebut.

Implementasi dari media tersebut, guru sebagai fasilitator tidak hanya sekadar memberikan pengidentifikasian karakter disiplin kepada siswa tetapi juga setiap karakter disiplin yang ada pada permainan tersebut harus diaplikasikan di lingkungan sekolah. Sehingga siswa mendapat respon (hasil) dari permainan tersebut dan secara tidak sengaja siswa akan mudah mengingat sikap disiplin yang harus diterapkan dan mengalami pembiasaan dalam melakukannya.

\section{KESIMPULAN}

Permainan Aku Anak Disiplin merupakan media pembelajaran pendidikan karakter yang mengajarkan mengenai pentingnya penerapan sikap disiplin dalam kehidupan sehari-hari. Permainan ini memberikan gambaran jelas kepada anak-anak tentang contoh-contoh sikap disiplin di 
rumah, di sekolah, dan di lingkungan masyarakat. Aku Anak Disiplin merupakan permainan yang diadaptasi dari permainan Ular Tangga yang dimodifikasi dengan kreatif dan inovatif sehingga menarik dan menyenangkan untuk dimainkan. Permainan ini dimainkan dengan menggunakan alat yang sama pada permainan Ular Tangga dan disertai dengan penggunaan tiga jenis kartu yaitu kartu anak disiplin (discipline child card), kartu prestasi (achievement card), dan kartu hukuman (penalty card).

Implementasi dari media tersebut, guru sebagai fasilitator tidak hanya sekadar memberikan pengidentifikasian karakter disiplin kepada siswa tetapi juga setiap karakter disiplin yang ada pada permainan tersebut harus diaplikasikan di lingkungan sekolah. Sehingga siswa mendapat respon (hasil) dari permainan tersebut dan secara tidak sengaja siswa akan mudah mengingat sikap disiplin yang harus diterapkan dan mengalami pembiasaan dalam melakukannya.

\section{DAFTAR PUSTAKA}

[1] Admin. (2013). Pembentukan Karakter Disiplin Anak Usia Remaja.

Dalam http://www.wartamadani.com/2013/04/pembentu kan-karakter-disiplin-anak-usia.html?m=1. Diakses pada tanggal 4 Oktober 2018 pukul 21.17 Wita.

[2] Aeni, Rizki. (2012). Karakteristik Anak Usia Sekolah Dasar.

Dalam http://www.rizardian.blogspot.co.id/2012/10/kara kteristik-anak-usia-sekolah-dasar.html?m=1.

Diakses pada tanggal 2 Oktober 2018 pukul 21.17 Wita.

[3] Anwar, Indra. (2011). Pembentukan Karakter Disiplin dalam Pembelajaran. Dalam http:// www. adrenalinpenulis. blogspot. co. id/2011/11/ pembentukan-karakter-disiplin-dalam-.html?m=1. Diakses pada tanggal 2 Oktober 2018 pukul 21.04 Wita.

[4] Bloom. (1979). Taxonomy of Educational Objectives Book 1: Cognitive Domain. London: Longman Group LTD.

[5] Danim, Sudarwan. (2010). Media Komunikasi Pendidikan: Pelayanan Profesional Pembelajaran. Jakarta: Bumi Aksara.

[6] Firdaus, A. M. (2019). Application Of Cooperative Learning Model Type Think Pair Share (Tps) On Mathematical Communication Ability. Daya Matematis: Jurnal Inovasi Pendidikan Matematika, 7(1), 59-68.
[7] Johansson, dkk. (2011). Practice for Teaching Moral Values in The Early Years: A Call for A Pedagogy of Participation. Education, Citizenship and Social Justice Journal, 6 (2), HIm. 109-124.

[8] Listyarti, Retno. (2012). Pendidikan Karakter dalam Metode Aktif, Inovatif, dan Kreatif. Jakarta: Penerbit Erlangga.

[9] S. Sadiman, Arief, dkk. (2005). Media Pendidikan: Pengertian, Pengembangan dan Pemanfaatannya. Jakarta: PT RajaGrafindo Persada.

[10] Saptono. (2011). Dimensi-Dimensi Pendidikan Karakter: Wawasan, Strategi, dan Langkah Praktis. Jakarta: Penerbit Erlangga.

[11] Sugirin. (2010). Affective Domain Development: Reality and Expectation. Jurnal Cakrawala Pendidikan, 3 (XXIX), Hal. 267-279.

[12] Suparno. (2012). Harapan untuk Kurikulum Baru. Kompas, 29 September 2018.

[13] Suryadi. (2012). Outlook 2025 Pembangunan Pendidikan Indonesia: Menuju Kualitas yang Berdaya Saing Secara Global (The Indonesian Education Outlook 20125: Toward A Sustainable World Class Quality Level). Jakarta: Badan Penelitian dan Pengembangan Kementerian Pendidikan dan Kebudayaan.

[14] Thomas Lickona. (2012). Character Matters (Persoalan Karakter) Bagaimana Membantu Anak Mengembangkan Penilaian yang Baik, Integritas, dan Kebijakan Penting Lainnya. Uyu Wahyudin dan Dasim Budimansyah, editor. Jakarta: PT Bumi Aksara.

[15] Wuryandani, Wuri, dkk. (2014). Pendidikan Karakter Disiplin di Sekolah. Jurnal Cakrawala Pendidikan, 3 (XXIX), Hal. 2-2. 